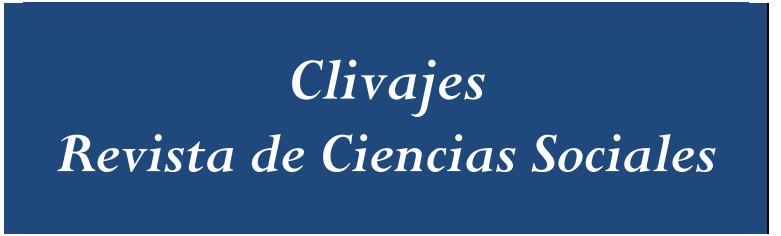

Clivajes. Revista de Ciencias Sociales ISSN: 2395-9495

http: / / cort.as/-8zT9 IIH-S, UV, México

María del Socorro Román Segura

PROYECTO ATG: MEDIO AMBIENTE Y AFECTACIONES SOCIALES A COMUNIDADES TOTONACAS DE PAPANTLA, VeracruZ, MÉXICO

Clivajes. Revista de Ciencias Sociales. Año V, número 9, enero-junio 2018, pp. 153-169. Instituto de Investigaciones Histórico-Sociales

Universidad Veracruzana. México

Recibido: 14-11-2017

Aceptado: 15-12-2017

Dictaminado: 16-12-2017

Publicado: 01-01-2018 


\title{
PROYECTO ATG: MEDIO AMBIENTE Y AFECTACIONES SOCIALES A COMUNIDADES TOTONACAS DE PAPANTLA, VERACRUZ, MÉXICO
}

\author{
María del Socorro Román Segura*
}

Resumen

Este trabajo explica cómo el proyecto Aceite Terciario del Golfo (ATG), emprendido por Petróleos Mexicanos (PEMEX) desde 2007, ha afectado la vida comunitaria y el entorno ecológico de las comunidades indígenas y campesinas del municipio de Papantla, Veracruz. Da cuenta de las acciones de resistencia y protesta de tales comunidades frente a la virtual invasión de muchas de sus tierras y territorios. Describe el marco jurídico de la industria del petróleo tras la Reforma Energética, centrando el interés en los instrumentos legales que garantizan el derecho de los pueblos indígenas y campesinos a un medio ambiente sano, al disfrute de sus medios de subsistencia y desarrollo, a poseer, utilizar y controlar sus tierras, territorios y recursos, a la autonomía y la libre determinación, así como a la consulta libre, previa y bien informada. Esta la primera aproximación de un estudio más amplio; manifiesta un genuino interés por discutir las características de un desarrollo regional armónico, moderno, basado en la impostergable justicia social y el respeto al equilibrio ecológico que, por siglos, las comunidades totonacas supieron preservar en la región natural que poblaron en el periodo clásico de Mesoamérica, con magníficos aportes culturales, propios de una civilización sofisticada y artística.

Palabras clave: Proyecto ATG, Resistencia social, Reforma Energética, Equilibrio ecológico y social

\section{LOS PUEBLOS INDÍGENAS Y SU DERECHO A UN MEDIO AMBIENTE SANO}

El párrafo cuarto del Artículo $4^{\circ}$ de la Constitución Política de los Estados Unidos Mexicanos establece claramente el derecho de toda persona a un medio ambiente sano para su desarrollo y bienestar, y que el Estado garantizará el respeto a ese desarrollo. Además, la Suprema Corte de Justicia de la Nación, en su Tesis I. 4 ${ }^{\circ}$. A.447 A (9a), que versa sobre el concepto, regulación y concreción de dicha garantía, indica que el mencionado derecho debe entenderse como un poder de exigencia y un deber de respeto erga omnes a preservar el entorno ambiental. En otras palabras, queda implícita la obligación correlativa de las autoridades a su vigilancia, conservación y garantía, y a que sean atendidas oportunamente las regulaciones pertinentes.

La Tesis indica, en ese sentido, que dicha potestad:

\footnotetext{
* Maestra en Gestión del Aprendizaje y Licenciada en Derecho por la Universidad Veracruzana, es catedrática en el Centro de Estudios Superiores del Norte de Veracruz y la Universidad Popular Autónoma de Veracruz.
} 
consagra el derecho subjetivo que tiene todo individuo a un medio adecuado para su desarrollo y bienestar. Asimismo, la preservación y restauración del equilibrio ecológico y la protección al medio ambiente en el territorio nacional está regulada directamente por la Carta Magna, dada la gran relevancia que tiene esta materia. En este sentido, la protección del medio ambiente y los recursos naturales es de tal importancia que significa el "interés social" de la sociedad mexicana e implica y justifica, en cuanto resulten indisponibles, restricciones estrictamente necesarias y conducentes a preservar y mantener ese interés, precisa y puntualmente, en las leyes que establecen el orden público (Suprema Corte de Justicia de la Nación, 2005).

De lo anterior se desprende que el derecho de las personas a un medio ambiente sano implica el adecuado uso y explotación de los recursos naturales; la preservación y restauración del equilibrio ecológico y el desarrollo sustentable, así como la necesidad de proteger y preservar tales recursos.

Los principios del párrafo cuatro del Artículo $4^{\circ}$ constitucional remiten al concepto de derechos colectivos de los pueblos, vinculados estrechamente a los derechos individuales de corte clásico, $\mathrm{y}$, por tanto, a la relación entre ambas categorías en la construcción del pluralismo jurídico, orientado a la protección de los derechos de comunidades y pueblos indígenas en su dimensión colectiva.

Tal como plantea Anglés (2015), en épocas relativamente recientes, pueblos y comunidades indígenas han luchado por reivindicar la tutela de sus derechos colectivos, lo cual implica un replanteamiento de la noción y construcción teórica de los derechos humanos, en una dimensión que supera el individualismo, para dar sentido y legitimidad al fundamento de otro tipo de derechos (precisamente los colectivos), como la cultura, el desarrollo, la identidad y la autonomía y libre determinación, en el marco de los cuales se integra el derecho de acceso preferente a los recursos naturales.

La historia de México muestra una larga serie de atropellos e injusticias cometidos contra las comunidades y los pueblos indígenas, resultado de la imposición de proyectos económicos excluyentes y elitistas. Estas comunidades primero fueron sometidas, cuando no se ajustaron a las leyes y mandatos del Estado y de los grupos dominantes, y luego se les excluyó del proyecto de nación.

En la actualidad, el proyecto hegemónico neoliberal se basa en la expansión de las actividades extractivas, como parte de un modelo económico, político y jurídico que legaliza la mercantilización de los bienes nacionales, la utilidad pública y el interés social. Esto acentúa la exclusión y la discriminación de los derechos colectivos, en tanto que, por un lado, apuesta a los proyectos de usufructo privado y, por otro, al despojo de los recursos de naturaleza colectiva (Anglés 2015); ejemplo destacado de ello es la reforma energética. 
Cabe señalar que, en 2007, la Asamblea General de la Organización de Naciones Unidas (ONU) aprobó la Declaración sobre los Derechos de los Pueblos Indígenas, en la cual constan, entre otros, los siguientes:

a) A participar en las cuestiones que afectan a sus derechos de conformidad con sus propios procedimientos e instituciones (Artículo 18).

b) A ser consultados. Los Estados celebrarán consultas y cooperarán de buena fe con los pueblos indígenas interesados por medio de sus instituciones representativas antes de adoptar y aplicar medidas legislativas o administrativas que los afecten, a fin de obtener su consentimiento libre, previo e informado (Artículo19).

c) A mantener y desarrollar sus sistemas e instituciones políticas, económicas y sociales, a que se les asegure el disfrute de sus propios medios de subsistencia y desarrollo y a dedicarse libremente a todas sus actividades económicas tradicionales y de otro tipo (Artículo 20).

d) A mantener y fortalecer su propia relación espiritual con las tierras, territorios, aguas, mares costeros y otros recursos que tradicionalmente han poseído, ocupado y utilizado (Artículo 25).

e) A poseer, utilizar, desarrollar y controlar las tierras, territorios y recursos que poseen en razón de la propiedad tradicional $u$ de otra forma tradicional de ocupación o utilización, así como aquellos que hayan adquirido de otra forma. Los Estados asegurarán el reconocimiento y protección jurídicos de esas tierras, territorios y recursos (Artículo 26).

f) A la conservación y protección del medio ambiente y de la capacidad productiva de sus tierras o territorios y recursos (Artículo 29).

g) A determinar y elaborar prioridades y estrategias para el desarrollo o la utilización de sus tierras o territorios y otros recursos. Los Estados celebrarán consultas y cooperarán de buena fe con los pueblos indígenas interesados por conducto de sus propias instituciones representativas a fin de obtener su consentimiento libre e informado antes de aprobar cualquier proyecto que afecte sus tierras o territorios y otros recursos, particularmente en relación con el desarrollo, la utilización o la explotación de recursos minerales, hídricos o de otro tipo (Artículo 32).

Debe recordarse que la ONU, a través del Pacto Internacional de Derechos Económicos, Sociales y Culturales (PIDESC), establece que la cuestión relativa al aprovechamiento de los recursos naturales y los derechos humanos supone una relación entre los pueblos y las comunidades indígenas, los gobiernos y el sector privado; relación que debe apuntalarse con el pleno reconocimiento de los derechos de estos colectivos a sus tierras y recursos naturales, lo que implica el ejercicio de su derecho a la libre determinación (ONU, 2003).

En este tenor de reconocimiento y protección de los derechos colectivos de los pueblos y las comunidades indígenas, la Organización Internacional del Trabajo (OIT) adoptó el Convenio 169 sobre Pueblos Indígenas y Tribales en Países Independientes, que 
reconoce la autonomía y el derecho al desarrollo de estos colectivos, los cuales están directamente asociados con el derecho a la consulta previa, libre e informada.

Tal como señala Anglés (2016: 32-33), la Ley de Hidrocarburos define a esta industria como "de la utilidad pública" (pese a que abre la puerta a los inversionistas privados), por lo que procede a la constitución de servidumbres legales, afirmando que "tendrán preferencia sobre cualquier aprovechamiento de la superficie o del subsuelo de los terrenos" (art. 96), y aun cuando refiere a una contraprestación para el uso, goce o afectación de los terrenos, bienes o derechos necesarios para negociar con los propietarios y titulares de aquellos (art. 100), también establece que el asignatario (empresa del Estado o privada) podrá promover ante Juez de Distrito en materia civil o Tribunal Unitario Agrario, la constitución de servidumbre legal de hidrocarburos o solicitar una mediación a la Secretaria de Desarrollo Agrario, Territorial y Urbano. Todo ello, a pesar de que esta misma Ley, en su art. 118, señala que los proyectos de infraestructura atenderán a los principios de sostenibilidad y respeto a los derechos humanos de las comunidades y pueblos de las regiones, debiendo proceder a una consulta previa, libre e informada (art.120).

La reforma energética de 2013 tuvo como objetivo central privatizar ese sector estratégico de nuestra economía. Y uno de los argumentos que esgrimían los defensores de tal reforma era que se buscaba aumentar, en algunos años, la producción de petróleo a más de 3.5 millones de barriles diarios de crudo. Meta que, por otro lado, estamos muy lejos de poder alcanzar. El investigador Jaime Cárdenas (2014) explica muy bien que el gobierno ha estado empecinado en incrementar esa producción y mantenerse en el esquema de exportador de petróleo crudo, y plantea una cuestión de vital importancia: "por qué se decide que casi la mitad de ese crudo se venda a los Estados Unidos, y no se almacene, refine o emplee en la industrialización de petroquímicos, actividades que generarían mayor valor agregado e implicarían mayor beneficio a la nación” (p. 144).

Ese cuestionamiento, después de tres años de formulado, mantiene plena vigencia. El mismo autor señala que la respuesta explica:

El saqueo de crudo que ha sufrido nuestro país en las últimas décadas, con enorme daño al pueblo de México y a las generaciones futuras, y está vinculada a los acuerdos explícitos y secretos del gobierno mexicano con el de los Estados Unidos. México se ha comprometido con ese gobierno, desde hace décadas, a proveerle más de un millón y medio de barriles de crudo al día, porque sin ellos, además de los millones de barriles que recibe Estados Unidos de otros proveedores, como Venezuela, Arabia Saudita o Canadá, la industria norteamericana colapsaría en poco tiempo -se calcula que nuestro vecino del norte requiere 18 millones de barriles diarios para mantener en funcionamiento su planta productiva (Cárdenas, 2014: 144). 
Por esta razón, México mantiene una política petrolera irracional y contraria al interés del país: "vendemos crudo, cuando deberíamos almacenarlo, refinarlo o destinarlo a la industria petroquímica nacional". Así, "lo extraemos irracionalmente para beneficio de la industria norteamericana". "No lo refinamos - añade Jaime Cárdenas-, ni construimos nuevas refinerías, porque las refinerías norteamericanas del Golfo de México paralizarían su producción”. Y en lo que toca a la petroquímica, el gobierno de México, "deliberadamente", ha desmantelado "esa industria nacional" para beneficiar a los intereses extranjeros, en detrimento de los intereses internos.

Esa es la "lógica económica" de esta reforma energética, y de ahí, precisamente, la urgencia de continuar adelante -torpemente- con una política exclusivamente extraccionista. En ese marco de referencia se explica el apuro por perforar a toda marcha, entre 2007 y 2012, en muchas zonas del llamado proyecto Aceite Terciario del Golfo, sin considerar, para nada, las afectaciones socioambientales que marcarían a la región en el período señalado.

\section{EL PROYECTO ATG: CRISIS ECOLÓGICA Y AFECTACIONES SOCIALES}

Chicontepec es un viejo yacimiento que ha tenido una producción continua desde hace más de medio siglo. Su explotación arranca en el lejano año de 1952, y hasta 1972, su producción fue mínima: unos cuantos barriles al día. Para finales de los años setenta, su producción levantó hasta alcanzar la cifra de poco más de 12000 barriles diarios. Más tarde, a comienzos de los noventa del siglo pasado, alcanzó picos de 16000 barriles y, a partir de 2003, su producción ya no es nada desdeñable, al situarse arriba de los 20000 barriles de aceite diarios (Barbosa, 2009: 3).

Durante el sexenio de Calderón, se anunció que Chicontepec, ahora calificado por los técnicos de Petróleos Mexicanos como el proyecto Aceite Terciario del Golfo (ATG), sería el principal proyecto productivo de Pemex. Dicho proyecto incluye una franja de unos 100 kilómetros de largo y 20 de ancho, entre Puebla y Veracruz. La dependencia encargada de administrarlo directamente es la Subdirección de la región norte de Pemex, con sede en Poza Rica, Veracruz, la cual anunció en 2007 que este proyecto exploratorio de perforación y producción se reactivaría con gran vigor. En aquel momento, las proyecciones de los técnicos de Petróleos Mexicanos, encabezados por el ingeniero Antonio Narváez, jefe del proyecto, eran muy optimistas, pues calculaban que el extenso yacimiento produciría, en un plazo muy cercano, entre 500000 y 900000 barriles diarios (Peláez, 2012). 
Al respecto, entre 2007 y 2012 se realizó una cuantiosa inversión que incluyó la terminación de cerca de mil pozos. Así, por ejemplo, en 2010, Pemex gastó en el proyecto 32000 millones de pesos; tres años después, otros 27000 millones (Gershenson, 2017b). Frente a estas enormes expectativas, los resultados productivos de Chicontepec han sido francamente modestos. Para 2008, ATG produjo 29000 barriles diarios; cuatro años después, en 2012, alcanzó su pico máximo de producción con 68000 barriles; actualmente, tal cifra se ubica en 39000 barriles. Este importante proyecto productivo ha sido motivo de intensos debates, pues se ha cuestionado las elevadas inversiones y sus pobres rendimientos (Barbosa, 2015: 154). Algunos opinan que, más bien, el citado proyecto ha servido como excusa para generar un despilfarro irresponsable, por decir lo menos. De tal forma que, por ejemplo, Antonio Gershenson, recientemente ha opinado que en el proyecto de Chicontepec se ha gastado un dineral, y señala contundentemente:

Su producción después de gastos en investigaciones para aumentarla, llegó a un máximo de 69 miles de barriles diarios, menos de 3 por ciento de la producción nacional. (...) La producción promedio por pozo fue bajando de 40 barriles diarios en 2008 a 17 barriles en 2016. Los mejores pozos marinos del sureste llegan a miles de barriles diarios inicialmente, y son muchísimo más baratos. Una ratería gigantesca en perjuicio de Pemex y del país (Gershenson, 2017b).

Esas elevadas inversiones provocaron la llegada, a Poza Rica y la región, de un gran número de compañías privadas que venían en busca del oro negro de nuestro subsuelo. Durante cinco años, se perforó febrilmente en los municipios de Alamo, Castillo de Teayo, Coatzintla, Poza Rica, Chicontepec, Ixhuatlán de Madero, Tihuatlán y Tecolutla, todos municipios del norte de Veracruz, además de otros tres del estado de Puebla (Francisco Mena, Pantepec y Venustiano Carraza). Eso ocurría en la esfera de la macroeconomía, al tiempo que, al microcosmos de las comunidades indígenas y campesinas de la región, llegaban el desastre ambiental, el trastrocamiento de la vida y las costumbres comunitarias, y la resistencia al despojo de tierras y tradiciones:

Lo que antes eran cerros llenos de verdor, hoy son páramos desolados en el Totonacapan. Lo mismo en localidades del municipio de Papantla, que en las de Coatzintla o Tihuatlán, los pobladores de esta región miran consternados, como su antiguo y apacible mundo agrario se ha convertido de cuatro años a la fecha, en una zona devastada por el atropellado avance de los trascabos Caterpillar o los camiones Macarios, que todo lo derrumban, arrollando milpas y naranjales (Román, 2009: 1).

Así describía un reportaje periodístico de 2009 lo que se vivía en esa zona del norte del estado de Veracruz. Y agregaba que si antes prevalecían el verdor exuberante del trópico 
húmedo, de las siembras agrícolas y de los pastizales, para la fecha ya eran omnipresentes los equipos de perforación, los transportes pesados (que ostentan los emblemas de compañías contratistas privadas), las cuadrillas de trabajadores y las carpas que funcionaban como improvisadas fondas. Además de ello, también habían eran evidentes los estragos de un desastre ecológico, que no apreciaban sólo aquellos que no querían ver la realidad inocultable.

La resistencia de las comunidades agrarias, mayoritariamente totonacas, acompañaba entonces a la desenfrenada y voraz perforación de las compañías privadas. Derrames de crudo, destrucción de plantíos y árboles; fugas de gas, contaminación severa de mantos acuíferos y deterioro ambiental fueron el centro de algunas denuncias y quejas de la población de las comunidades afectadas por un proyecto que no respetado el entorno ecológico regional. De 2008 a estos días, la comunidad campesina ha expresado su descontento frente a los múltiples atropellos y agresiones a su medio ambiente y su modo de vida, derivados de la ejecución del proyecto ATG. Los ejemplos de estas acciones de resistencia son muchos. Aquí mostramos sólo unos cuantos.

El 11 de febrero de 2009, campesinos de 50 localidades de Papantla bloquearon los accesos hacia las instalaciones de varios pozos petroleros, para exigir a la paraestatal de Pemex que cumpla con los compromisos pactados con anterioridad (el 19 de abril 2008). Entre las peticiones que, aseguraban los quejosos, estaban pendientes, mencionaron el pago por daños a cultivos, asfaltado de carreteras, reconstrucción de puentes destruidos, introducción de sistemas de agua potable, drenajes y dotación de tuberías (De Luna, 2009a).

De acuerdo con el reportero Francisco de Luna, Policarpio Pérez Castillo, presidente del comisariado ejidal El Triunfo, e integrante del Movimiento Campesino Papanteco, explicó entonces que había transcurrido un año desde que realizaran un bloqueo previo para exigir las citadas reivindicaciones para las comunidades donde se hallan los pozos petroleros. En aquella fecha (2008), Óscar Torres Plasencia, jefe de la Unidad de Administración de Asuntos Externos de Pemex y Luis Octavio Alcázar Cansino (también funcionario de la paraestatal), se habían comprometido a hacer llegar los apoyos a las comunidades quejosas.

En esta ocasión, en el movimiento de protesta participaron habitantes de las comunidades La Lagunilla, Santa Agueda, Remolino, San Andrés, Francisco Villa, Gildardo Muñoz, Vista Hermosa, Francisco I. Madero, Plan de Hidalgo, Jorge Serdán, Luis Echeverría, Arroyo del Arco, La Grandeza, Los Kilómetros, La Guásima, Escolín, José María Morelos, Lázaro Cárdenas, San José las Lajas, El Triunfo y Donato Márquez. Los dirigentes de las comunidades señalaron que: 
es urgente realizar la reparación de muchas carreteras, pues los camiones de carga pesada que le trabajan a Pemex y a sus compañías contratistas, son las que han destrozado las carpetas asfálticas, dejando grandes hoyancos, los que a su vez han provocado incontables accidentes a quienes transitan por ellas. Mientras que en las rúas de terracería tales camiones han producido enormes huecos y lagunas de lodazales que impiden el paso libre de camiones y dificultan el transitar de los pobladores de la región (De Luna, 2009a).

En este sentido, el subagente de la comunidad La Laguna, Severiano Santés García, informó que los constantes derrames de petróleo "han dañado los cultivos, en grandes extensiones de tierra”, y por esa razón se vieron obligados a cerrar el acceso de un promedio de cien pozos, tan sólo en el municipio de Papantla:

Pemex y las compañías, lejos de ser una ayuda para el pueblo de nuestro municipio han resultado ser un factor destructivo para la vida comunitaria, amenazante para la salud y el bienestar de nuestras familias, y está asesinando el equilibrio ecológico de nuestra zona”, opinaron algunos de los dirigentes de los inconformes. Igualmente acusaron que son víctimas del engaño por parte de los funcionarios de la paraestatal, quienes en un principio se comprometieron en apoyar sus peticiones y que ahora "sólo se hacen los desentendidos" (De Luna, 2009a).

Otra de sus quejas remite a los daños en cultivos de cítricos, milpa e incluso en los mantos acuíferos que utilizan para el riego del sembradío y para el propio consumo y uso diario de los habitantes: “están contaminados por los constantes derrames de hidrocarburo", manifestó Norma Maldonado Hernández, agente municipal en Donato Márquez, quien además dio a conocer que las tuberías de Pemex se encuentran deterioradas, oxidadas y carcomidas, lo que ha originado que los derrames sean constantes y afecten a los sembradíos.

El viernes 2 de octubre del 2009, de nueva cuenta un gran número de indígenas de comunidades agrarias del municipio de Papantla bloquearon varios tramos carreteros para protestar porque Pemex no había dado respuesta puntual a diversas demandas, quejas y peticiones de las comunidades papantecas. Los periódicos locales informaron que "en el bloqueo de la carretera Papantla-María de la Torre participan alrededor de mil indígenas de diversas comunidades, lo que ha impedido el tránsito de vehículos que quedaron varados y dejando incomunicados a varios poblados de la sierra del Totonacapan” (de Luna, 2009b).

Asimismo, se daba a conocer que los campesinos habían determinado bloquear los accesos a los pozos petroleros donde Pemex realizaba trabajos de explotación, en protesta por los daños en caminos provocados por los camiones pesados de las empresas contratistas de la entonces paraestatal. El agente municipal de la congregación Gildardo 
Muñoz, Juan Díaz Hernández, señaló que "la protesta se originó ante el incumplimiento de Pemex para reparar los caminos que conducen a sus comunidades": "En diversas ocasiones -dijo- han exigido a Pemex reparar los caminos y puentes dañados y, para ello, se han firmado diversos convenios donde se han establecido compromisos; sin embargo, no ha cumplido ni tampoco ha reparado las afectaciones causadas a sus parcelas".

Acompañado por autoridades de por lo menos cincuenta comunidades de la zona, el agente municipal subrayó que su única demanda es que "Pemex cumpla los compromisos firmados desde hace dos años, en el sentido de reconstruir los caminos, remediación de suelos y pago de cultivos afectados”. Refirió que desde que la paraestatal inició los trabajos del proyecto de Aceite Terciario en la región: "nos han afectado nuestros caminos y los cultivos de maíz", y a pesar de los reclamos: "lo único que hemos tenido son promesas". Desde hace dos años -señaló-, "los directivos de Pemex nos han estado dando largas a pesar de que se firman minutas y acuerdos que nunca cumplen”. Debido a esta situación, habían decidido movilizarse, bloquear los accesos a los pozos de exploración y tomar la carretera.

En efecto, quien recorra los caminos rurales de esta región puede constatar, a simple vista, que tales rúas están completamente destrozadas y que el continuo tránsito de equipos pesados y camionetas de las compañías privadas generan enormes nubes de polvo, las cuales van dañando evidentemente la salud de los habitantes de las comunidades que se ubican cerca de tales caminos, provocando el aumento significativo de casos de asma y otras enfermedades respiratorias, según los agentes municipales de tales localidades.

En el mismo tenor, diversos personajes de la región, como el expresidente municipal de Papantla, Federico Márquez, o el catedrático de la Universidad Pedagógica Nacional, Felipe Reboredo, han señalado que con la intensificación de las actividades de perforación, por parte de las empresas privadas, se han recrudecido otros problemas, como la desertificación y el desmonte de amplias áreas, anteriormente forestales. El segundo de ellos -al preguntarle si desde la reactivación de los trabajos de perforación los cambios en las comunidades habían sido para bien, contestó tajante: "para nada; al contrario, observamos un recrudecimiento de la pobreza y la marginación social”.

En diversas fechas, entre agosto de 2009 y septiembre de 2011, la autora de este trabajo, en compañía de los periodistas Mario Román y Jorge Huerta, realizó varios recorridos por algunas áreas del municipio papanteco, en los que pudo apreciar, de forma directa e in situ, tales problemáticas. En la comunidad de "Jorge Serdán” del municipio mencionado, observamos que el arroyo que surtía de agua a dicha comunidad estaba totalmente contaminado por el escurrimiento de crudo y las emanaciones de gases de un pozo cercano de Pemex, sin que la empresa petrolera se abocara a resolver el caso. 
Acompañados del subagente municipal, Arnulfo Cano, estuvimos en el lugar de los hechos: el sitio en el que, en días pasados, se observó que el arroyo que corre paralelo al poblado se había llenado de chapo. Las evidencias eran muy claras y estaban ahí, pues se apreciaba que dicho cuerpo de agua estaba completamente dominado por una mancha oscura, densa, característica de los hidrocarburos.

Avanzando por la ladera de un cerro, pudimos llegar hasta donde se ubica un agujero en el suelo, por donde brota gas, con el peculiar aroma a "huevo podrido". Los técnicos de Pemex tuvieron a bien poner, como única medida de precaución, una endeble y ridícula cinta de plástico, color anaranjado. El resultado es que los pobladores de Jorge Serdán no pueden beber agua de donde siempre han bebido, es decir, de su arroyo cercano. Los directivos de la paraestatal han determinado proporcionar agua de garrafones para que la población pueda contar con el vital líquido durante varias semanas. "El progreso - señalaba entonces el expresidente municipal de Papantla, Federico Márquez- no se detiene ante nada. Y muchas veces pasa por encima de viejas tradiciones y costumbres, pues no siempre se aviene con el respeto a la identidad cultural de los pueblos que se ponen por delante de él”.

Los pobladores de Jorge Serdán nos comentaron que desde que se presentó la contaminación, muchos de ellos presentaron fuertes "comezones" y manchas en la piel, además de irritación en los ojos, síntomas de que el deterioro del medio ambiente se refleja casi siempre en problemas de salud en los seres humanos y animales de la región. En otras comunidades, como El Triunfo, los habitantes señalaron que varias casas habían sufrido cuarteadoras en sus paredes, debido al uso de dinamita en los procesos perforatorios. Con angustia, algunos habitantes aseguran que "Pemex sólo nos ha dado puras promesas, pero hasta ahora no ha respondido por los daños a nuestras casas, y ya han pasado meses desde entonces".

El señor Alberto Francisco del Valle nos mostró las cuarteaduras de su casa indicó que la paraestatal ya está informada de esa situación y "no había hecho nada". En esta misma comunidad, se nos informó que los propietarios habían venido vendiendo sus predios. Así, nos aseguraron que el señor Alfonso Pérez - por citar sólo un caso- vendió a Pemex un predio de dos hectáreas por 600000 pesos, y ahora, la compañía Weatherfort realiza trabajos de perforación en ese lugar.

En la comunidad José María Morelos, el señor Bastián afirmó que continuamente sufren apagones, porque las compañías revientan los cables: “y ya usted adivinará cómo pasamos muchas noches, sin electricidad, sin ventiladores, ahogándonos de calor”. Indica que también hay escurrimiento de aguas sucias y de aceite, que afectan a varias zonas de su comunidad: "estos señores no se detienen ante nada y nunca oyen nuestras denuncias; a 
ellos solo les ha importar perforar a toda prisa y lo que les pase a nuestra gente, lo tiene sin cuidado".

Motivo de queja recurrente de las comunidades agrarias papantecas, es el destrozo en los caminos, provocado por los equipos pesados de las compañías que circulan en el área. Para la señora G. Hernández, los equipos pesados son un peligro, pues "al pasar, cimbran las casas, y las camionetas de las compañías van como locas”, y también lo son por el escurrimiento de aguas y líquidos con sustancias químicas no identificadas. Además, los habitantes se lamentan por la destrucción del cableado eléctrico, pues aseguran que muchos aparatos electrodomésticos se han visto afectados por eso.

Al respecto, Pemex y las compañías privadas se avienen a una vieja tradición de la política y los negocios mexicanos: la impunidad; y, haciendo uso de un viejo refrán salinista, a las comunidades indígenas "ni las ven, ni las oyen”, y las justas demandas y exigencias de las comunidades quedan aplazadas para siempre, frente a la apertura económica y las exigencias de una impostergable e impositiva reforma energética.

Durante nuestros mencionados recorridos, observamos cómo la maquinaria de las compañías, literalmente, pulverizaba áreas agrícolas completas. Fue el caso de un cerro, antes lleno de naranjales, que, poco a poco, “quedaba pelón”, al ser aplastados los árboles frutales. A propósito de ello, un veterano luchador social de la región, botánico y agrarista de cepa, don R. Jiménez, nos dijo: "esa riqueza agrícola y natural se derriba en unos cuantos minutos, pero su perdida es lamentable, pues los arbolitos tardan años en crecer y dar frutos; pronto tendremos sólo desierto, si alguien no para esta locura y esta gran impostura”.

Todas las actividades descritas son factores que se agregan a los efectos palpables del cambio climático en la región. La creciente desertificación, las sequías y el aumento notable de la temperatura ambiental parecen generar actualmente un proceso en el que el verdor y la vitalidad del trópico van cediendo el paso a un páramo desolado y triste.

\section{FRACKING: UN ELEMENTO MÁS DE INESTABILIDAD REGIONAL}

A lo antes planteado, debemos agregar que la técnica de perforación, basada en el fracking, agudiza la problemática ambiental que afecta a las comunidades agrarias e indígenas de la región norte de Veracruz. Sabemos que la aprobación y el impulso de la práctica de fracturación hidráulica ofracking, en el marco de la reforma energética privatizadora, pone en riesgo el futuro de la nación mexicana. Esta práctica implica la inyección al subsuelo de miles de metros cúbicos de agua mezclada con peligrosas substancias químicas, precisamente con el fin de fracturar la tierra para extraer gas y petróleo crudo. De tal 
forma, el fracking no es una práctica compatible con el desarrollo sustentable o sostenible; de hecho, en varios países ya ha sido prohibida o suspendida (Ackerman, 2015).

Cabe apuntar aquí que por cada pozo perforado, la controvertida fracturación hidráulica utiliza entre 3500 y 25000 metros cúbicos de fluido, del cual 98\% es agua y el restante, arena y sustancias químicas. Las investigaciones correspondientes muestran la presencia de sustancias tóxicas, como metales pesados (arsénico, plomo y/o mercurio), e inclusive partículas radioactivas (uranio, radón, torio) que de manera natural se encuentran en el subsuelo, pero son arrastradas con las aguas residuales hacia la superficie. Además, dichas "substancias pueden encontrar una vía hacia las fuentes subterráneas de agua potable si las fracturas se extienden más allá de la formación explotada, o si las tuberías de revestimiento o el cemento alrededor de la perforación ceden a las presiones ejercidas" durante el procedimiento. Obviamente, estas substancias químicas son altamente dañinas para el ser humano y los ecosistemas (Anglés, 2016: 35).

La técnica del fracking también implica afectaciones a la atmósfera por el uso de sustancias tóxicas; específicamente el benceno, que incrementa la posibilidad de desarrollar cáncer (especialmente leucemia) y otras afectaciones en la sangre.

Finalmente, es preciso señalar la necesidad de que los impactos regionales de este método de extracción sean ampliamente analizados y registrados. La contaminación y afectaciones a las comunidades indígenas son evidentes, y es responsabilidad de todos asumir un compromiso para evitar que el neoliberalismo, acentuado en la reforma a la Ley de Hidrocarburos, imponga a rajatabla sus reglas. Debemos apostar por una verdadera independencia y soberanía energética, en la que no estemos sometidos a los dictados y atropellos de las empresa extranjeras.

\section{REFERENCIAS}

ACKeRMAN, J. M. (Coord.) (2016). Introducción a Fracking: ¿Qué es y cómo evitar que acabe con México?". México: Universidad Nacional Autónoma de México (UNAM)-Instituto de Investigaciones Jurídicas (IIJ), Tirant Humanidades.

Alanís, G. A. (2014). Derecho a un medio ambiente sano. México: UnAm.

ANGLÉS HeRnÁNDEZ, M. (2016). Fracturación hidráulica y su impacto en los derechos humanos a un medio ambiente sano, al agua y a la salud. En ACKERMAN, J. M. (Coord.), Fracking: ¿Qué es y cómo evitar que acabe con México? México UNAM- IIJ, Tirant Humanidades. 
. (2015). La reforma en materia de hidrocarburos en México, como parte del proyecto neoliberal hegemónico violatorio de derechos humanos. UNAM- IIJ.

. (2014). El derecho al desarrollo y a los recursos naturales de los pueblos originarios de México en un contexto de discriminación y exclusión. En Sin derechos. Exclusión y discriminación en el México Actual. México: UNAM- IIJ.

Barbosa Cano, F. (2009). Chicontepec: la apuesta de Pemex. Petróleo y electricidad (123). - (2015), Prospectiva de la industria petrolera en México a partir de la reforma Energética 2013-2014. En OropezA, A. (Coord.), Reforma Energética y Desarrollo Industrial. México: UNAM- IIJ, Instituto para el Desarrollo Industrial y el Crecimiento Económico, A.C.

CÁRdenas Gracia, J. (2014). Crítica a la reforma constitucional energética de 2013. México: UNAM- IIJ.

IFE (2013). Constitución Política De Los Estados Unidos Mexicanos. México.

De LunA, F. (2009a, febrero 12). Protestan comunidades de Papantla. Noreste.

. (2009b, octubre 3). Bloquean carreteras comunidades por daño de Pemex. Recuperado de http://www.informatepr.com

Gershenson, A. (2017a, enero 15). Desde inicios del sexenio, la promesa de los 3 millones. La Jornada.

. (2017b, enero 27). La producción de Pemex sigue bajando. La Jornada.

ONU (2007). Declaración de las Naciones Unidas sobre los Derechos de los Pueblos Indígenas. Resolución 61 /295. Nueva York: Asamblea General de la ONU.

PelÁEz, R. (2012). Entrevista exclusiva al Ing. Antonio Narváez, nuevo Subdirector de Producción Norte de Pemex Exploración y Producción. Revista Petroquimix.

Román del VAlle, M. A. (2009, agosto 20). El desastre ecológico y el proyecto de Chicontepec. Recuperado de http://www.informatepr.com

SCJN (2005, enero). Tesis I. $4^{\circ}$.A.447 A (9a.), Medio ambiente adecuado para el desarrollo y bienestar. Concepto, regulación y concreción de esa garantía, Semanario Judicial de la Federación y su Gaceta, t. XXI, Nueva Época. 


\section{ANEXO FOTOGRÁFICO}

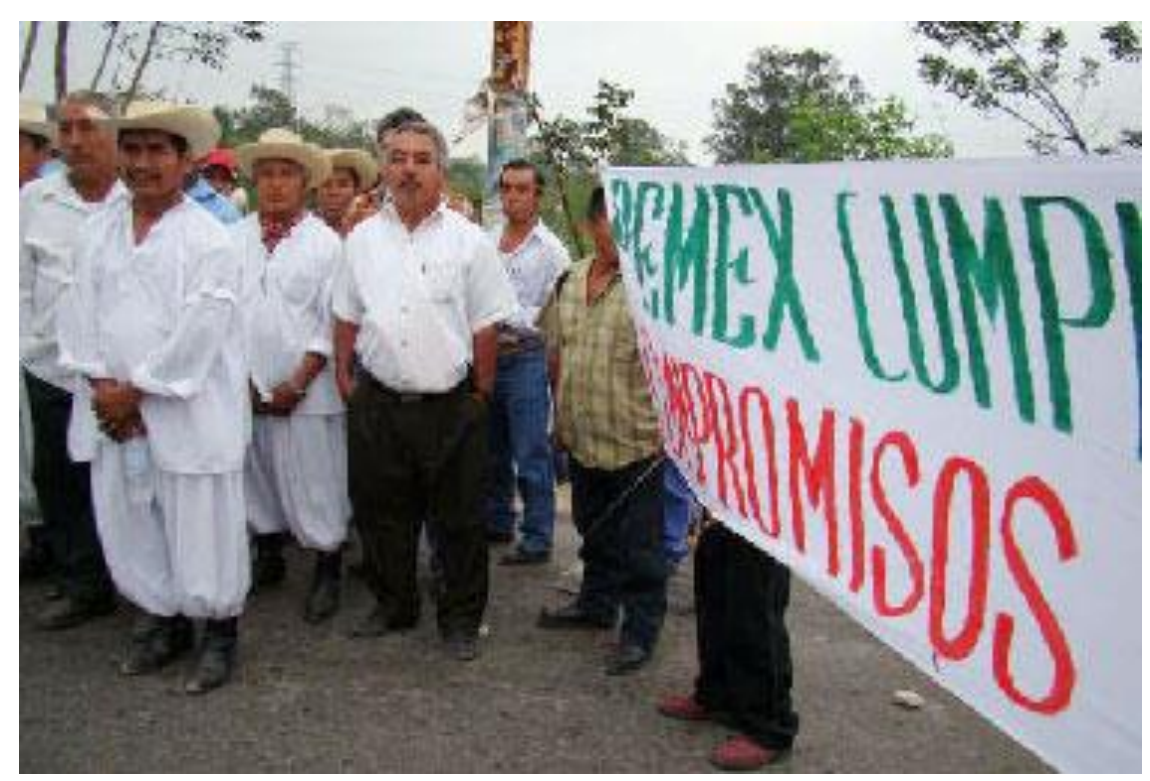

Las comunidades totonacas han protestado, bloqueando carreteras y accesos a los pozos petroleros.

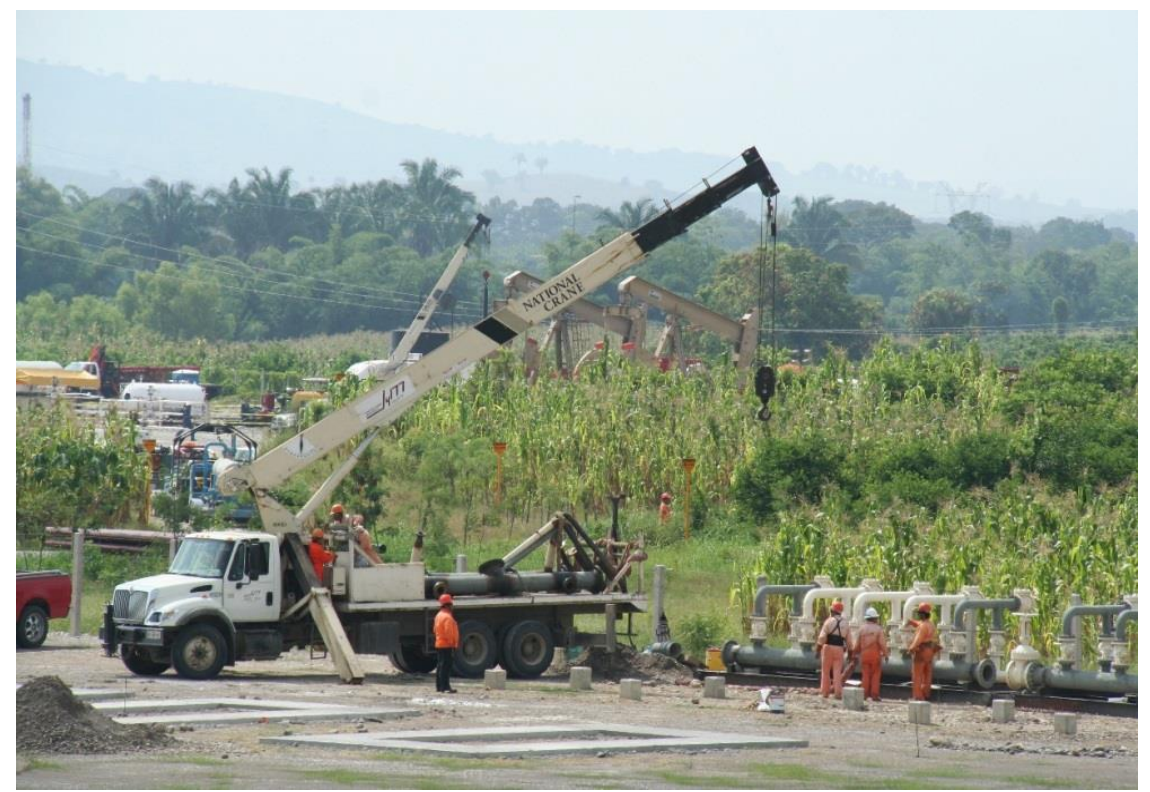

Perforando y afectando áreas agrícolas 


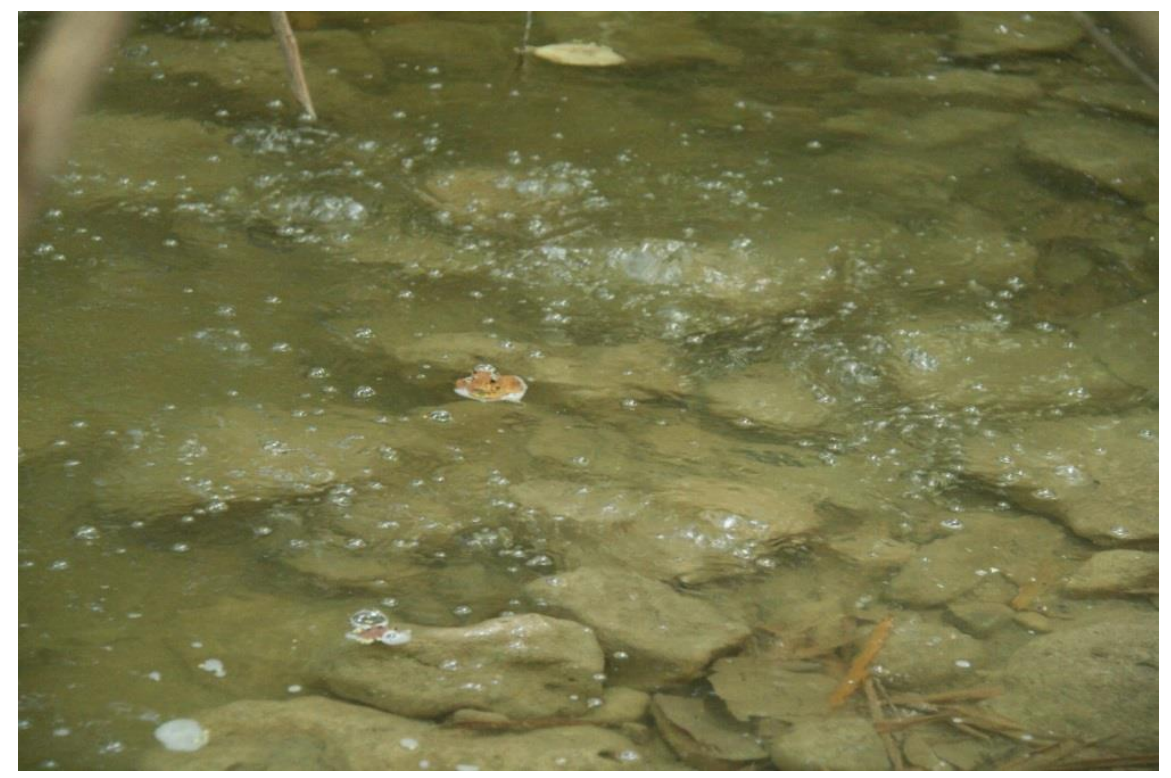

Es evidente la contaminación de los cuerpos de agua.

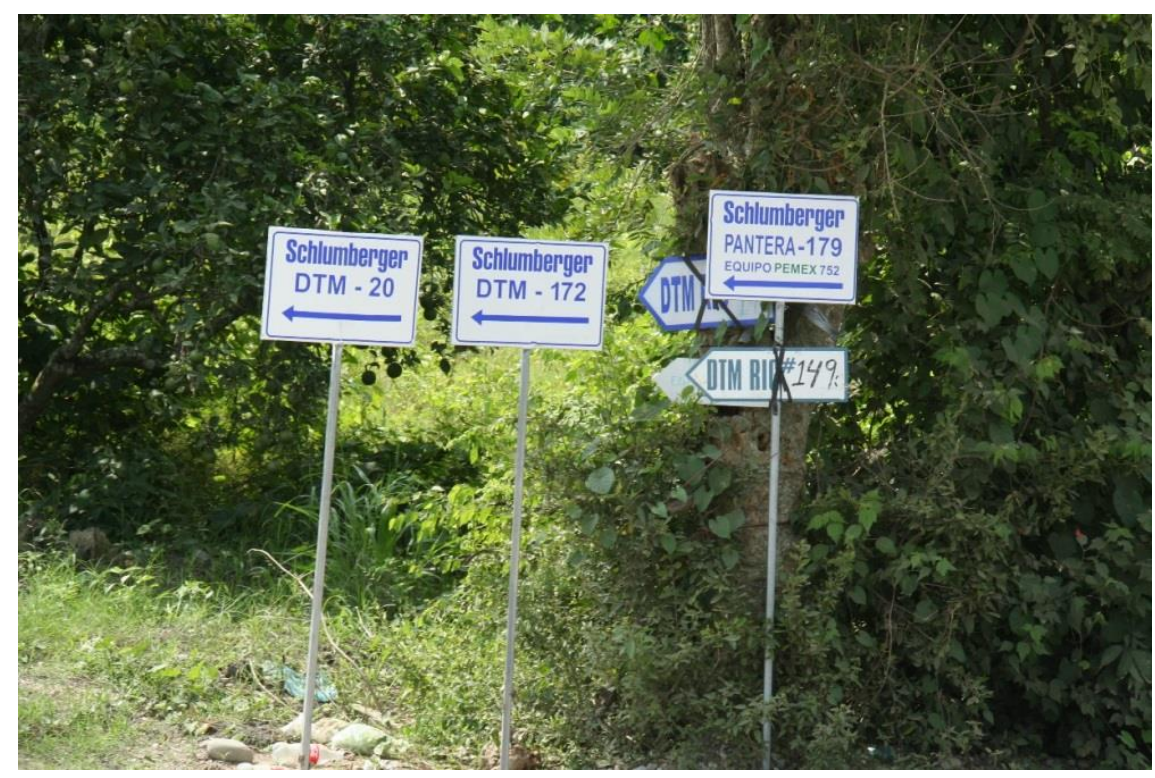

Las compañías privadas perforan febrilmente. 


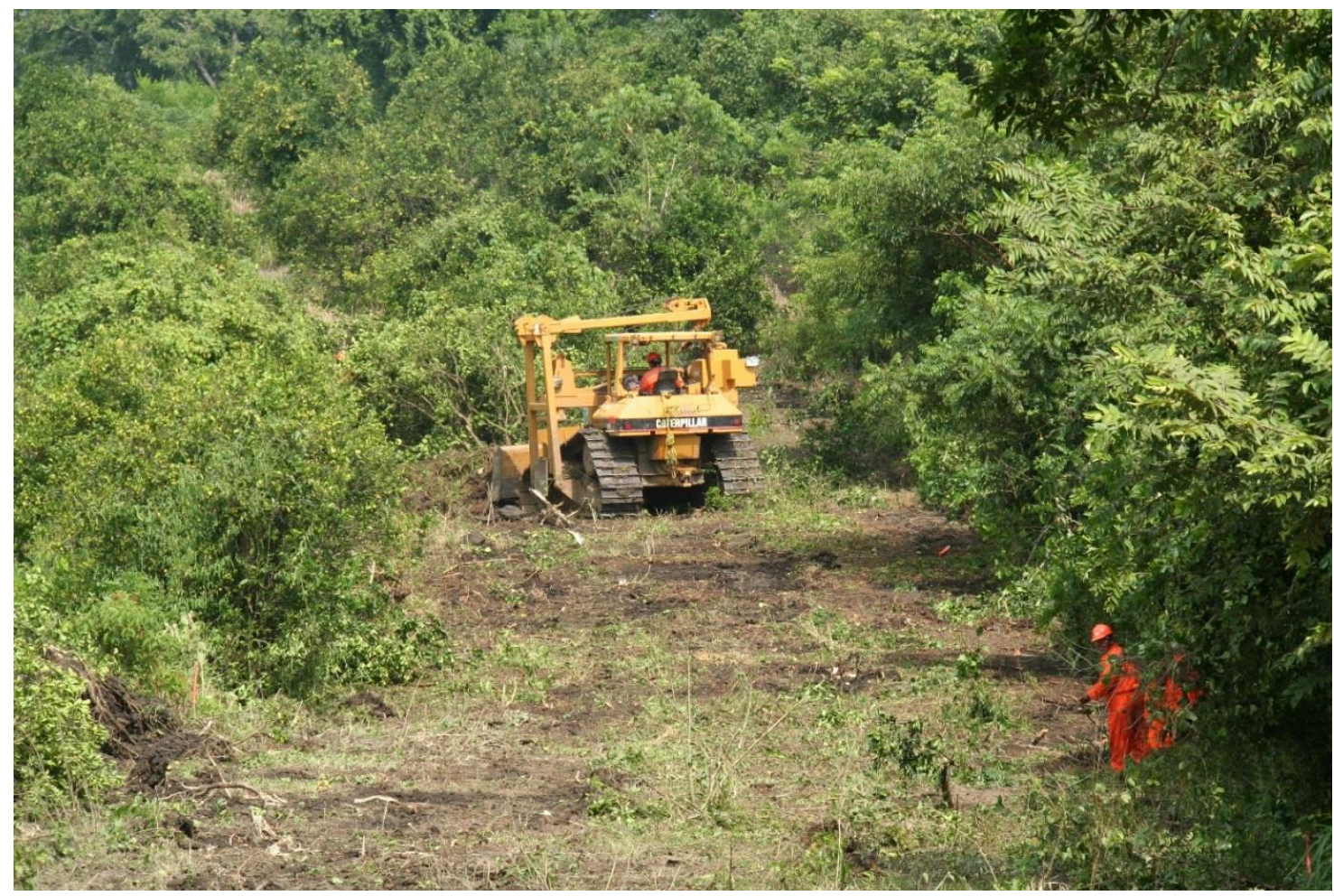

Los naranjales son derribados para perforar pozos. 